\title{
El pasado en el presente de Sevilla: la Giralda como monumento disputado (1198-1568)
}

Covarrubias, en su Tesoro de la Lengua Castellana -publicado por primera vez en 1611, aunque comenzado a redactar bastante antes-, define la voz monumento de la siguiente manera: "Vulgarmente se toma por el túmulo y aparato que se haze en toda la Yglesia Católica el Jueves y Viernes Santo, donde puesta un arca en forma de sepulcro se encierra el Santissimo Sacramento en memoria del sepulcro en que estuvo aquellos tres dias el cuerpo de Nuestro Redentor Jesu Christo". Pero, en rigor, añade, cambiando súbitamente al latín: "monumentum est quidquid nos movet, ut tituli, sepulcra, statuae, fama, porticus, theatra, carmina, bistoriae, documenta, praeceptiones, sapientum monita, libri et caetera eiusmodi. ${ }^{1}$. En este sentido etimológico y más amplio, pues, el monumento resulta ser todo aquello que estimula nuestra memoria, que nos avisa y advierte, y su tipología en consecuencia es sumamente variada: sepulcros, inscripciones, pórticos, estatuas, teatros, etc.

Nos interesa destacar aquí esta función de recordatorio que constituye la raíz misma del concepto de monumento porque es un aspecto generalmente olvidado hoy, cuando tendemos a asociar con este término la magnificencia, una escala desmesurada o, más simplemente, una superior dimensión estética. Y nos interesa recordarlo, además, en su función como instrumento conformador de la memoria colectiva, particularmente en las sociedades más antiguas, en las que las vías de comunicación y difusión eran de índole distinta a las actuales. Portador de unos determinados significados y valores (aunque, como veremos, capaz no sólo de cambiarlos, sino de asumir otros radicalmente antitéticos), el monumento supone por otro lado un hiato en la continuidad del tejido urbano; un fragmento de excepcionalidad que, por ello mismo, concita la atención de cuantos lo ven.

La Giralda de Sevilla resume y compendia de modo ejemplar estas diversas funciones del monumento. Desde sus orígenes parece haber

1 Sebastián DE COVARRubias, Tesoro de la lengua castellana o española (Madrid, 1611). Cito por la edición facsímil de la de Barcelona, 1943 (Barcelona, 1987). 
existido conciencia de su singularidad; caso prácticamente sin precedentes en la arquitectura del mundo islámico, conocemos los nombres de los dos alarifes que intervinieron en su construcción: Ahmed ben Baso y Ali de Gomara. Incluso se ha conservado el nombre del artífice que, el 10 de marzo de 1198, remató el alminar con las cuatro enormes bolas doradas de su yamur: el siciliano Abul Layz ${ }^{2}$.

Debemos imaginar la Giralda en su entorno primitivo, destacando por su enorme altura sobre un caserío muy bajo; un elocuente signo del poder de la dinastía almohade. No es casual que en la otra capital del reino, en la Kutubiya de Marrakesh, se construyera una réplica de la torre sevillana. Hay que tener presente, además, las circunstancias históricas en que se construyó: la decisión de los monarcas almohades de construir una nueva alcaicería y una nueva mezquita mayor, en perjuicio de la venerable mezquita de Ibn Adabas y de la vieja alcaicería entre las actuales plazas del Salvador y de la Alfalfa, supuso una violenta alteración de la estructura urbana, que se había mantenido relativamente estable desde época romana, siendo recibida con fuertes resistencias. Era preciso, pues, un edificio capaz de "convencer" por su propia escala, por su propia ostentación de poder ${ }^{3}$.

Pero la Giralda expresaba la gloria de los soberanos almohades de una manera más sutil además. Rodrigo Caro recoge la noticia de que, para la cimentación de la torre, los alarifes musulmanes "arrojaron todos los antiguos ornamentos que los romanos avian dexado en Sevilla, para suplir con ellos y llenar el gran fosso y juntamente para que fuesse firme el edificio que sobre esta gran cepa y rayz avian de edificar" ${ }^{*}$. Recientísimos sondeos en la cimentación de la torre no han revelado la presencia de tales restos romanos; sin embargo, a simple vista podemos apreciar todavía hoy dos inscripciones romanas cuidadosamente empotradas en una esquina de la base, que pueden haber dado origen a esta leyenda. Ahora bien, la meticulosa ubicación de las inscripciones romanas en el ángulo de la base del alminar almohade contradice la noción de que pudieran haber sido utilizadas como material de relleno. Por el contrario, cabe interpretar el

- Fl más reciente trabajo sobre la Giralda, que incluye un regesto documental con aportaciones inéditas en A. Jiménez Martin y J. M. Cabeza. Turris Fortissima. Documentos sobre la construcción. acrecentamiento y restauración de la Giralda (Sevilla, 1988), 2 vols.

Sobre la evolución urbana de la Sevilla islámica véase A. JiMÉnez MARTín, «Análisis formal y desarrollo histórico de la Sevilla medieval., en AA. VV., La arquitectura de nuestra ciudad (Sevilla, 1981).

+ R. CARO, Antigüedades y Principado de la Ilustrissima Ciudad de Sevilla... (SeviIla, 1034), fol. 49. Existe edición facsímil. Sevilla, 1982. 
hecho como una demostración simbólica del poder del Islam sobre los "romanos", que es como se conocía a los reyes cristianos. De este modo, la torre, alzándose sobre los restos de los infieles y coronada por las bolas doradas del yamur, se convertía, en cierta medida, en una gráfica ilustración de la victoria obtenida por los musulmanes sobre Alfonso VIII en Alarcos en 1195, tan sólo tres años antes de la terminación de las obras 5 .

Todos estos factores confirieron un gran prestigio al monumento, como se refleja en la literatura eulogística de los autores musulmanes, y quizás por ello mismo vino a convertirse en símbolo eminente de la ciudad. En efecto, en las negociaciones llevadas a cabo en noviembre de 1248 entre el ejército cristiano sitiador y los musulmanes sevillanos derrotados podemos percibir un curioso forcejeo: solicitando éstos autorización para poder derribar el alminar de su mezquita antes de abandonar la ciudad, y contestando los primeros por boca del Infante don Alfonso que "si solamente derribasen un ladrillo de los que estavan encima por aquello no le fincaría moro ni mora en Sevilla que no matase..... Del mismo modo, y una vez firmada la capitulación, la primera provisión del rey don Fernando fue colocar su enseña en lo más alto de la torre, siendo sustituida inmediatamente después por la cruz y las campanas emblemáticas del culto cristiano ${ }^{6}$.

Desde muy pronto, como podemos ver, la Giralda asume -pars pro toto- la representación simbólica de la ciudad: su esbelto perfil compendia y resume la complejidad urbana. Para los musulmanes vencidos, en cierta manera, el haberla destruido antes de evacuar la ciudad hubiera significado perder "algo menos". Para los caballeros cristianos, por el contrario, la cruz y las campanas sobre el remate constituían la más contundente imagen de su triunfo. $Y$ en este sentido, cabe destacar aquí que no se produce ruptura en la literatura eulogística sobre la torre al cambiar la ciudad de dueños: las crónicas cristianas abundan en los mismos tópicos que las musulmanas sobre su gran "beldat y altesa”.

Excepto por el añadido de la cruz y las campanas, la Giralda se mantuvo prácticamente inalterada durante casi un siglo después de la conquista de la ciudad; el 24 de agosto de 1356, sin embargo, un terremoto dio en tierra con el yamur o remate de bolas doradas. Éste fue sustituido por una mezquina espadana, como lo podemos ver en numerosos testi-

\footnotetext{
5 Para otros ejemplos de uso "políticon de restos antiguos, véase M. GREENHALGH, "Ipsa ruina docet: l'uso dell'antico nel Medioevo", en Memoria dell'antico nell'arte italiana, vol. I (Turín, 1984).

6 R. Menéndez Pidal (ed.), Primera Crónica General de España que mandó componer Alfonso X el Sabio y se continuaba bajo Sancho IV en 1289 (Madrid, 1955).
} 
monios gráficos, especialmente en documentos del cabildo catedralicio que la había elegido como emblema, flanqueada por las simbólicas jarras de azucenas ${ }^{7}$.

Así había de permanecer de nuevo durante un largo período, dos siglos, hasta que encontramos una nueva y extraordinaria manipulación del monumento. Ello no quiere decir que la Giralda hubiese perdido protagonismo como monumento celebrativo. Significativamente, la encontramos citada en el testamento del rey don Pedro, quien legó la suma de 3.000 doblas de oro para su reparación. Por otro lado, figura prominentemente en las "alegrías" - fundamentalmente fuegos artificiales y músicacon que las buenas nuevas de la guerra con Granada son recibidas en la ciudad.

Ahora bien, a mediados del siglo XVI podemos detectar una nueva preocupación con el aspecto poco "decoroso" de la torre. Este cambio de actitud debe ser visto en el contexto de renovación clasicista que, a partir sobre todo de las bodas del emperador un cuarto de siglo antes, se había generalizado en la ciudad. Pero responde además a motivaciones más especificas. El primer indicio de este cambio de actitud lo encontramos en 1555, cuando un arquitecto local, Diego de Vergara, presentó ante el Cabildo Catedralicio un proyecto para dotar a la torre de nuevo remate: un chapitel de forma piramidal que habría de ir forrado de "alatón morisco" para que brillase al sol ${ }^{\text {. }}$.

Significativamente, este proyecto -que, en su sencillez, sin duda habría enfatizado el carácter islámico del fuste de la torre-- fue rechazado por los capitulares. Sólo tres años más tarde, sin embargo, y a pesar de los informes adversos de varios expertos que temían por la estabilidad del monumento, los mismos capitulares aprobaban el proyecto presentado por el arquitecto cordobés Hernán Ruiz II, que otorgaría a la Giralda su perfil hoy familiar".

Esta decisión de los capitulares debe ser analizada en el momento histórico en que se produjo. En 1558 España se encontraba en una difícil coyuntura histórica: desde mediados del siglo había ido en aumento la presión musulmana, tanto por parte de los turcos como por parte de los piratas berberiscos, produciéndose con regularidad desembarcos y razzias.

M." Dolores CABRA LOREDO y Elena M." SANTIAgO PAEZ, Iconografía de Sevilla. Tomo primero, 1400-1650 (Madrid, 1988), láms. 1-19.

* El documento fue publicado por primera vez por T. FAlCón MÁrQLEz, La Catedral de Setilla. Estudio Arquitectónico (Sevilla, 1980), p. 159.

- A. Jimenez MARTin. "El Patio de los Naranjos y la Giralda., en AA. VV., La Catedral de Serilla (Sevilla, 1984). 
A ello había que añadir el peligro, siempre latente, de que estas fuerzas se unieran a la población morisca del interior ${ }^{10}$. Por otro lado, era también patente el aumento de la disidencia que, por utilizar un término contemporáneo, podemos denominar como "luterana", más preocupante ahora al extenderse entre las capas sociales más elevadas ${ }^{11}$. Hacia mediados del siglo, pues, en España, y en términos generales, existía en las esferas del poder una conciencia difusa, pero crecientemente articulada, de que la política conciliatoria y tolerante practicada años atrás había fracasado en ambos frentes. La represión antimorisca se había iniciado, desde luego, mucho tiempo antes: desde que en 1499 el cardenal Cisneros abandonara la suave política de persuasión del arzobispo granadino fray Hernando de Talavera, poniendo en práctica una política de bautismos masivos y forzosos, quema de libros musulmanes, prohibición de uso de su lengua, de sus trajes y costumbres, etc. Política que fue contestada con alzamientos locales a lo largo de la primera mitad del siglo.

Lo mismo cabe decir, mutatis mutandis, respecto al problema de la disidencia "luterana"; la política vacilante de la primera mitad del siglo, debida a la existencia en el propio entorno del Emperador de un núcleo de erasmistas y "espirituales", experimentará en los años de mediados del siglo una transformación radical. Con razón se ha visto como principal protagonista de este cambio de actitud al arzobispo de Sevilla e inquisidor general, Fernando de Valdés: "severo perseguidor de la herética pravedad y de la Católica Fe vigilantísimo defensor", según reza la inscripción de su sepulcro. Aunque el nombramiento de Valdés como inquisidor general tuvo lugar en 1547, a la muerte de su antecesor, el arzobispo Manrique, el año clave de su actuación fue sin duda el de 1558, cuando se iniciaron los terribles autos de fe en Valladolid y Sevilla ${ }^{12}$.

Ahora bien, como hemos visto, 1558 es también el año en que el Cabildo Catedralicio sevillano acepta el proyecto de reforma del alminar musulmán, presentado por Hernán Ruiz II. Es preciso ahondar en esta coincidencia cronológica. Desde 1556 el Cabildo, de un lado, y el inquisidor y arzobispo sevillano, por otro, habían protagonizado una situación de abierto enfrentamiento, al designar el primero al doctor Constantino

1" J. Reglé, "La cuestión morisca y la coyuntura internacional en tiempos de Felipe IIn, en Estudios sobre los Moriscos (Barcelona, 1974).

11 M. ${ }^{\text {a }}$ PAZ ASPE, "El cambio de rumbo en la espiritualidad española a mediados del siglo XVI", en A. ALCALÁ y otros, Inquisición española y mentalidad inquisitorial (Barcelona, 1984).

12 M. BATAILLON, Erasmo y España. Estudios sobre la bistoria espiritual del siglo XVI (México, 1966). 
Ponce de la Fuente para suplir la canonjía vacante por la muerte del doctor Juan Gil o Egidio, procesado por la Inquisición, designación a la que se oponía el inquisidor Valdés. En 1558, es decir, el mismo año en que se aprueba el proyecto de Ruiz, el nuevo canónigo magistral, Constantino Ponce de la Fuente, fue a su vez encarcelado por la Inquisición, muriendo en el castillo de San Jorge al poco tiempo en circunstancias no muy claras ${ }^{13}$. Cuando dos años más tarde, al mismo tiempo que se levantan los andamios del nuevo remate de la Giralda, sean quemados en efigie en auto de fe los doctores Egidio y De la Fuente, puede decirse, sin embargo, que este enfrentamiento ha terminado. El Cabildo Catedralicio, una institución corporativamente favorable a la espiritualidad más moderna e intimista, capitula ante el poder del arzobispo inquisidor Valdés. Y la Giralda, construida según reza la inscripción conmemorativa gracias "a su favor y aliento", puede entenderse como signo visible de este acatamiento y como manifiesto de los "tiempos recios" que corren.

El proyecto ideado por Hernán Ruiz para rematar el alminar almohade ha llegado a nuestros días incompleto; en efecto, se han perdido las pinturas que, realizadas por Luis de Vargas, recubrían el cuerpo de la torre. Pero diversos testimonios gráficos contemporáneos, o poco posteriores, permiten su reconstrucción. En primer lugar, se pintó la fábrica de ladrillo imitando una fábrica de cantería; luego, alojados en los arquillos ciegos y en otros puntos estratégicos, se situaron 68 imágenes de Apóstoles, Padres de la Iglesia y Santos y Santas locales. El remate arquitectónico propiamente dicho adopta la forma de un templete triunfal, similar a los que el propio Hernán Ruiz había construido, en materiales no duraderos, como monumento de Semana Santa o túmulos para las exequias reales. Por fin, todo ello culminaba en la gigantesca estatua de la Fe, Fidei lictricis Colossus, según la define la inscripción conmemorativa.

Con este proyecto se conseguian dos objetivos complementarios: en primer lugar, neutralizar visualmente un imponente testimonio de la dominación musulmana en España. En un momento - la quinta década del siglo xvi- que, como ya hemos señalado, se caracteriza por el aumento de la presión turco-berberisca, lo musulmán -lejos de ser visto como signos de un vencido inofensivo- comienza a ser considerado con creciente hostilidad. Esta "cristianización" de la Giralda encuentra de hecho un gráfico correlato en los decretos por los que se obliga a los moriscos a "cristianizar" su lengua, su indumentaria y sus costumbres, que culmina-

13 K. WAGNER, El Doctor Constantino Ponce de la Fuente. El bombre y su biblioteca (Sevilla, 19-9) 
rían con la rebelión de las Alpujarras en 1568, por otra curiosa coincidencia el año de terminación de la nueva Giralda ${ }^{14}$.

Pero la manipulación de la torre almohade para hacerle perder sus raíces va todavía más allá. En 1587, Alonso de Morgado escribe que, según la opinión de "algunos de nuestros más curiosos arquitectos", resulta imposible de creer que "un edificio tan suntuoso, tan alto, $\tan$ fuerte y magnífico sea obra de moros, sino que es de muy antes y de tiempo de gentiles..." ${ }^{15}$.

Que tan extravagante opinión no era un mero desvarío erudito, sino que gozaba de cierta difusión, lo confirma una tabla del retablo de los Evangelistas en la catedral de Sevilla, retablo firmado por Hernando de Sturmio en 1555. Aquí, en un paisaje de ruinas clasicistas evocador de la Sevilla "de los gentiles", es decir, de los romanos, podemos ver el martirio de las Santas Justa y Rufina presidido por la torre almohade. En términos contemporáneos, pues, el proyecto de Hernán Ruiz "restauraba" la torre, devolviéndola a sus raíces "gentiles". Esta asombrosa manipulación no carecía, por otro lado, de antecedentes; poco antes, el excelente arqueólogo Ambrosio de Morales, en las Antigüedades de las ciudades de España, que añade al final de su Crónica General (1574-86), afirmaba respecto al alminar de la mezquita cordobesa que "más tiene de obra romana que de morisca", pues está hecho "todo con medida, correspondencia y proporción Romana". Morales, como Argote, poseía suficientes conocimientos arqueológicos como para creer sus propias palabras. Pero el efecto buscado no se hizo esperar: el alminar cordobés fue también "restaurado", envolviendo su fuste a partir de 1593 otro Hernán Ruiz, el tercero de la dinastía, en una funda clasicista ${ }^{16}$.

Pero si, con estas operaciones - provistas incluso, como hemos visto, de coartada ideológica-, la presencia "morisca" de estos notables monumentos quedaba visualmente neutralizada, sometida a exorcismo, debemos analizar de igual modo su instrumentalización al servicio de la ortodoxia contrarreformista. Desgraciadamente no conocemos en todos sus detalles el "programa" de las pinturas realizadas por Luis de Vargas, "su moço y un oficial flamenco", en la caña de la torre, y hoy casi en su totalidad borradas por la lluvia. Sin embargo, la presencia de Apóstoles, Padres de

14 M. García ARenal, Los Moriscos (Madrid, 1975).

15 AlONSO DE MORGADO, Historia de Sevilla (Sevilla, 1587), fol. 91v.

16 F. DE OCAMPO, Crónica General de España... (Madrid, 1792), vol. 10, p. 54. Sobre estas tergiversaciones renacentistas de la arquitectura musulmana véase especialmente V. NiETO ALCAIDE, „El mito de la arquitectura árabe, lo imaginario y el sueño de la ciudad clásica", en Fragmentos, núm. 8-9 (1986). 
la Iglesia y Santos y Santas locales sugiere que éste debía subrayar la jerarquía, la "cadena de mando" de la institución eclesial, fundada sobre la revelación y la tradición, en abierta polémica con las tendencias más individualistas $\mathrm{e}$ intimistas de la sensibilidad religiosa reformada.

Coronando el templete triunfal, en fin, la figura del Giraldillo remata también el discurso programático de la torre cristianizada. El significado concreto de esta colosal figura de bronce (7,52 metros) ha provocado en tiempo reciente un intenso debate, sucediéndose las más peregrinas interpretaciones. Los documentos contemporáneos, sin embargo, son bastante explícitos, desde la lápida conmemorativa ya citada -donde es descrita como "Coloso de la Fe Vencedora" a un documento de la contabilidad catedralicia, donde se la cita como "(estatua de la) Fe e Triumpho de la Iglesia". Lo singular, lo que puede prestarse a confusión, es que se ha omitido el atributo tradicional de la Fe, el cáliz, sustituyéndola por una palma de victoria. Sin embargo, el otro atributo tradicional, la banderola o estandarte, sí se ha mantenido. Ello sugiere que la efigie, probablemente ideada por el canónigo Francisco Pacheco, buscaba enfatizar su aspecto triunfal: imagen que era reforzada por el casco, la coraza y las grebas clasicistas. La Fe victoriosa, auspiciada por el arzobispo e inquisidor general Valdés, no es pues la figura convencional transmitida desde la Edad Media que recoge mansamente en su cáliz la sangre de Cristo, sino una auténtica Palas Atenea cristiana, una guerrera armada cuya sombra recorre el perimetro de la ciudad.

A lo largo de cuatro siglos, como hemos visto, la utilización del monumento -ese hito urbano excepcional que debe "movernos", según Covarrubias- ha ido superponiendo a su arquitectura significados no ya diversos, sino contradictorios. $Y$ es en esa capacidad para asumir contenidos donde reside la vitalidad del monumento.

VICENTE LLEÓ CAÑal Universidad de Sevilla 


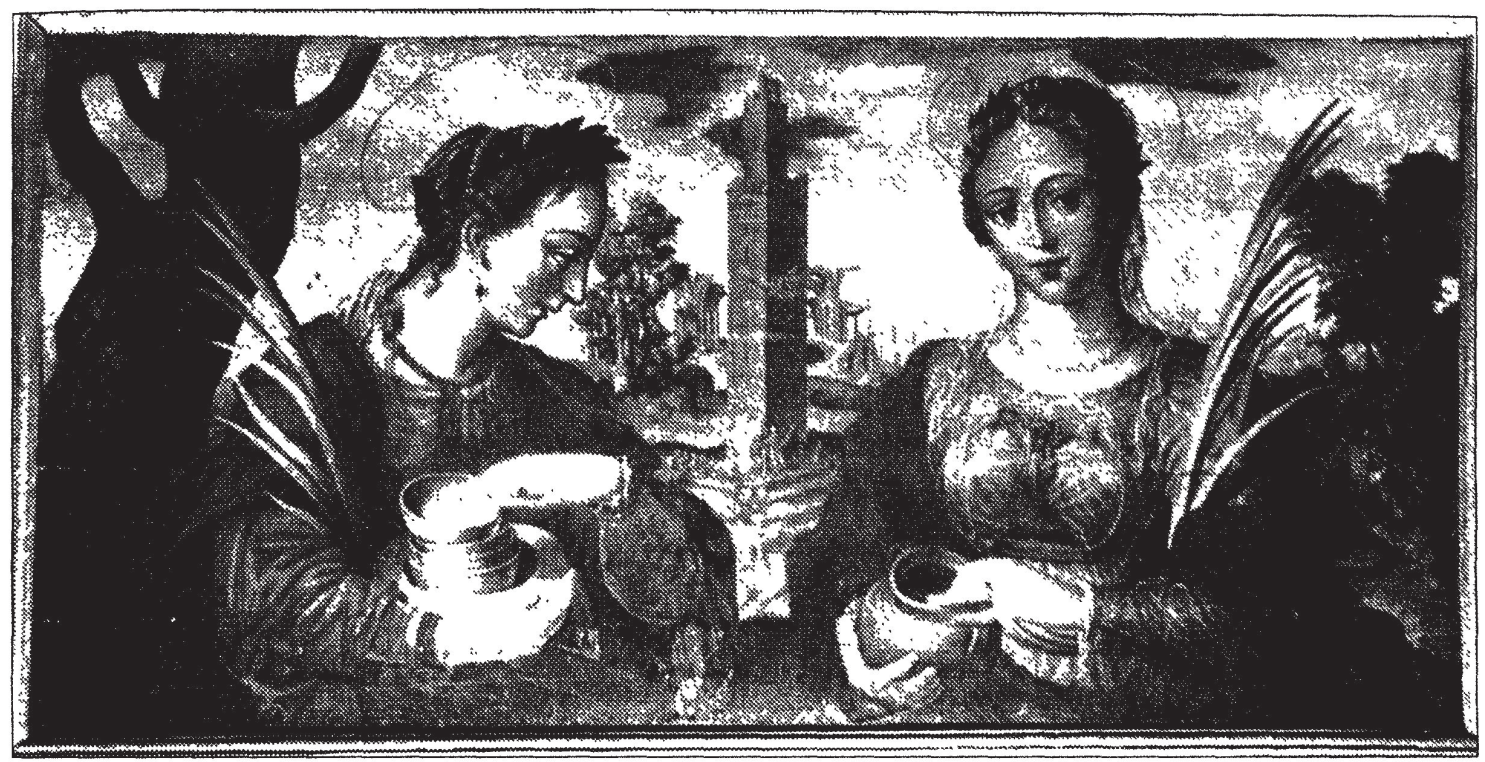

FIG. 1.-La Giralda antes de su transformación. Santas Justa y Rufina. Catedral de Sevilla, óleo sobre tabla (1553-1555)

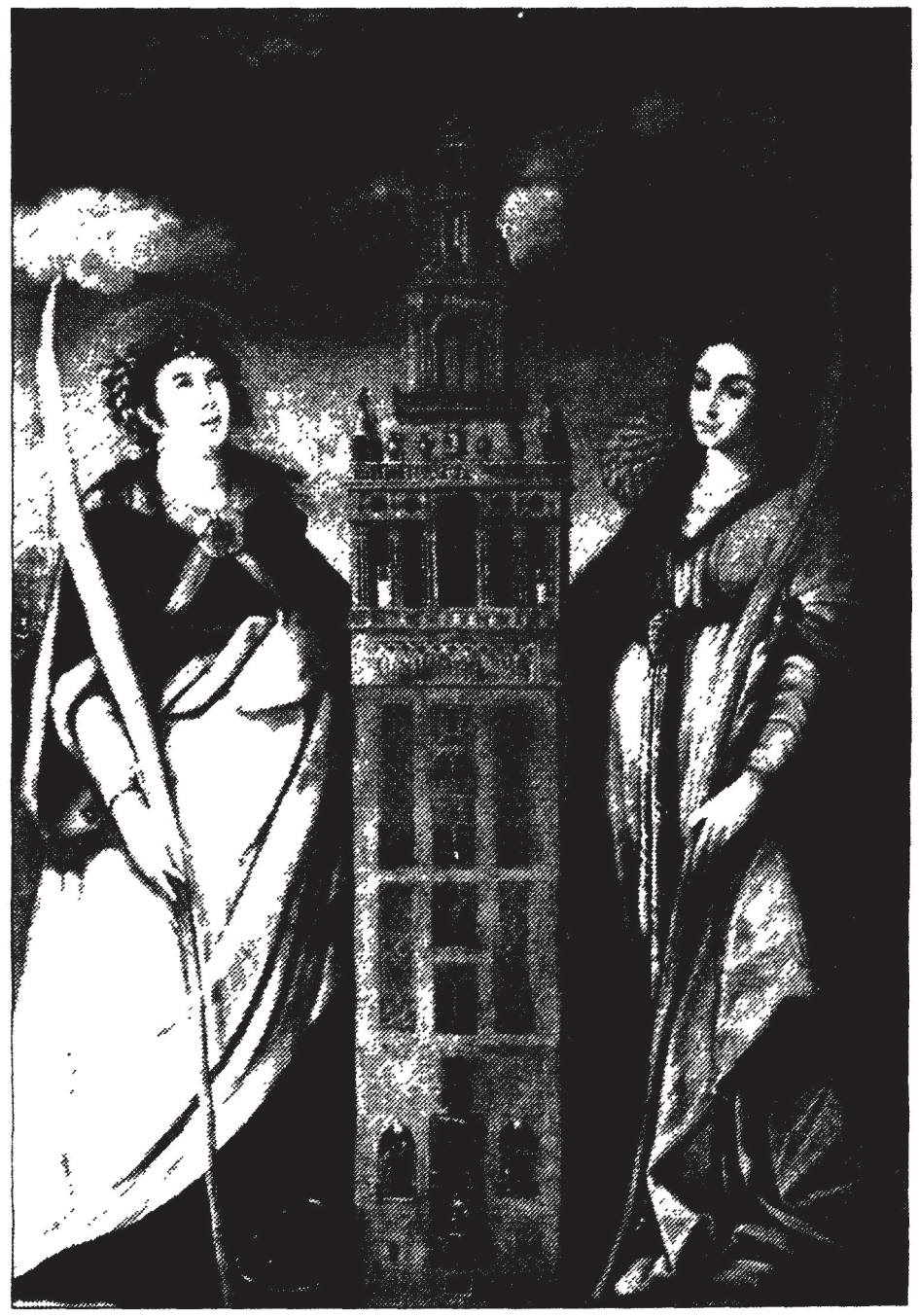

FIG. 2.-La Giralda como emblema de la ciudad, ya con su nuevo coronamiento. Esquivel, Santas Justa y Rufina. 
Los monumentos, como hitos urbanos, son susceptibles de asumir significados diversos y aun contrapuestos. Un caso notable en este sentido lo constituye la Giralda de Sevilla. Construida a fines del s. XII, como emblema del triunfo musulmán sobre los cristianos, identificados como "romanos" (se empotran lápidas e inscripciones en su base), a mediados del siglo XVI sufre una importante transformación destinada ahora a convertirlo en insignia del triunfo cristiano sobre la fe musulmana.

As urban landmarks, monuments are capable of assuming the most diverse, even contradictory meanings. A remarkable instance of the above is the Giralda tower in the Cathedral of Sevilla. Built at the end of the XIIth C. as part of the mosque, as a sign of the moslem triumph over the christians (identified as "romans", hence the roman inscriptions embedded at the base), in the second half of the XVIth C. underwent an important reform designed to transform it in an emblem of the christian triumph over the moslems. 